\title{
Body composition an analysis from evolution and feeding
}

\section{Book review}

“¡Come y Ponte en Forma! Desmontando los mitos de la nutrición deportiva " is the latest book by the Doctor in Functional and Molecular Biology Ramón de Cangas Morán. The dietitian nutritionist and sanitary biologist author, of Spanish nationality, President of the Alimenta Tu Salud Foundation, Director of the Scientific Committee of the National Network Your Nutritionist, Member of the Consultative Body of the General Council of Dieticians Nutritionists of Spain and Academic Number of the Spanish Academy of Human Nutrition and Dietetics. Winner of the recognition: Award to the Leader in Research and Health Sciences for the Benefit of Humanity

2017-2018, awarded by the International Society of Research, Health, Business Development and Technologies (SIISDET). ${ }^{1}$

With a prologue from the Doctor in Nutrition and Physical Activity Antonio Jesús Sánchez Oliver, 45 topics, and 137 scientific researches referenced, "i Come y Ponte en Forma!", it deals with, based on scientific evidence, to deny various food myths and misconceptions, spread among athletes and the general population around the world. Although it is not specifically a dietary planning book for athletes, it has great utility in proposing healthier and more sustainable food options that improve performance and overall health.

"The paleodiet, a healthy option, not a better or necessary option" is in principle the book, the key element that allows the author to make a detailed analysis of the evolutionary development driven by mutations and the culture of cooking the food acquired with the controlled use of fire, through the foundation of dietary evolutionary theories such as the starch theory, the synthesis of beta lactase after weaning, and that of the saving gene. In this sense, the author states that, "... genes evolve according to the evolutionary advantages offered by certain mutations ... in only 4000 years a whole population can go from not being able to eat a food to being able to eat it ..."

The author argues, through the evolutionary theory that relates obesity to the mutation of the gene that encodes the enzyme uricase (saving gene) and that increases the levels of uric acid in blood, how an excess of fructose and other simple sugars, it can favor the accumulation of fat and the elevation of uric acid levels favoring insulin resistance and the development of several of the components of the metabolic syndrome. In relation to this, he presents the hypothesis, raised by various authors, that it is possible that this mutation in our simian ancestors turned us into energy savers, which at the time was positive since in times of scarcity it allowed survival; but in times of abundance like the present ones it facilitates the increase of the corporal fat conditioning the development of diseases like the obesity, diabetes mellitus type 2, and arterial hypertension. Therefore, he reaffirms the recommendation to limit the consumption of simple sugars preferably to fructose from fresh fruit, avoiding other sources, in addition to increasing physical activity, in order to minimize the harmful effects of this saving gene.

According to the author, what matters in the control of body weight is to reduce fat mass, preserving the muscle at all costs, as a sustained
Volume 3 Issue 4 - 2018

\author{
Ajete Careaga Susan Belkis \\ Faculty of Medical Sciences, University of Medical Sciences \\ Artemisa, Cuba
}

Correspondence: Ajete Careaga Susan Belkis, Faculty of Medical Sciences, University of Medical Sciences Artemisa, Cuba, Email susanb@infomed.sld.cu

Received: July 17, 2018| Published: August 31, 2018

loss of muscle mass in the long term, means less autonomy, greater dependence, greater risk of suffering certain diseases and a significant reduction of the basal metabolism and total energy expenditure. Therefore, he recommends increasing physical activity with a proper diet, alluding to the fact that although it is true that even with specific training the gain of muscle mass is slow, the increase in physical exercise, even at advanced ages, can prevent the loss of muscle mass.

To preserve the muscle, the author proposes to carry out several food frequencies per day. It is based on the positioning of the International Society of Sports Nutrition and certain recently published studies, which support the fact that eating 5 or 6 times a day can be a priori advantage at least in the maintenance of muscle mass. By making several meals a day, with the right amount of protein, even in a hypocaloric diet, it can help maintain muscle mass, helping to stabilize blood glucose levels and therefore insulin, and increasing the levels of the growth hormone, which achieves an anabolic effect that conditions an increase in muscle mass. Drawing on his experience of more than a decade as a dietitian nutritionist in consultation, he argues that by making several meals a day, the patient has greater adherence to the diet and it is easier to reject unhealthy high-calorie foods.

According to the most recent scientific evidence, whole and especially fermented dairy products can help to improve physical resistance and promote the recovery of muscle mass, in addition to having a preventive effect on cardiovascular and metabolic health, and this is how the author explains it, making reference to more than a dozen of investigations on the subject and to the consensus document "Nutritional and Metabolic Importance of the Milk" in which several universities and scientific societies of Spain intervened. As the author says, based on the growing evidence in favor of whole dairy, “... the dietary strategy of reducing the intake of these foods in order to reduce the intake of saturated fats and, in exchange, take more carbohydrates (without take into account the type of carbohydrates) could be a nutritional error. "With respect to which he argues that not all saturated fatty acids behave in the same way, and that certain saturated fatty acids present in whole milk products such as margaric acid and transpalmitoleate can have a positive effect on cardiovascular health, since the nutritional composition of the matrix in which these specific fatty acids are found influences. In this sense, he stands out that the evidence points at more in favor of the consumption of unsweetened whole natural yogurt, which can achieve a synergistic 
effect between its components (probiotics, bioactive peptides, specific saturated fatty acids, conjugated linoleic acid, calcium) with proven benefits on cardiovascular and metabolic health and the preservation of muscle mass.

Finally, Dr. de Cangas, opts for the consumption of "real food", specifically for the Mediterranean diet, which is superior in scientific evidence, varied in food, sustainable and it respects the culinary traditions. However, he points out that certain foods (which are limited within the food pyramids of the whole world), consumed occasionally within the context of a healthy diet, do not pose a risk to health. He also warns that the food industry can do much for the health of the population, that it should demand more responsible publicity and improvement in the formulations of some of its products. However, he indicates that we must educate athletes and the general population in nutrition, and above all we must educate children from school with a nutrition course from now on.

“¡Come y Ponte en Forma! Desmontando los mitos de la nutrición deportiva ", in my point of view is a book that provides theoretical and practical tools for decision making, applicable not only to sports nutrition but to all specialties of human nutrition. I believe that this book is very useful for dietitians-nutritionists and health professionals from different branches, as well as for the general population, as it contributes to the deepening of knowledge and the updating of the scientific endorsement of each of the topics addressed in it, and by explaining them in a comprehensible way, it allows to reach easily the conclusion. In my opinion, it is a really interesting book, written in a critical way, that invites reflection and debate among professionals from the most diverse branches, including the food industry sector and the pharmaceutical industry. Undoubtedly, it is a text of extraordinary scientific and human value, very necessary for the society of these times, where chronic diseases related to nutrition are increasingly prevalent, derived above all from excess in food, conditioned in most cases by the lack of early and timely education in relation to healthy eating habits. I recommend the use of this book as a reference bibliography for research in different medical specialties and particularly in all fields of Human Nutrition and Dietetics.

\section{Acknowledgments}

None.

\section{Conflict of interest}

The author declares no conflict of interest.

\section{References}

1. Ramón de Cangas ¡Come y Ponte en Forma! Desmontando los mitos de la nutrición deportiva. Madrid: Ediciones Oberón (G.A.). 2018;205. 